C Elsevier/INRA

Original article

\title{
The impact of sperm motility on non-return rate in preselected dairy bulls
}

\author{
EM Stålhammar, L Janson, J Philipsson \\ Department of Animal Breeding and Genetics, Swedish University of Agricultural Sciences, \\ Box 7023, S-750 07 Uppsala, Sweden
}

(Received 26 March 1993; accepted 9 November 1993)

\begin{abstract}
Summary - The objective of this study was to investigate whether variation in sperm motility, after preselection of bulls for this trait, has any impact on the non-return rate (NRR). The material consisted of pre- and post-freezing motility records and NRR records from 117 young Al bulls with at least 100 services each. Data representing 2 breeds at 2 different $\mathrm{Al}$ studs were analysed within studs. Both quadratic and linear regression analyses were performed to describe the relationship when the fixed effects of herd-year, month and order number of the insemination, parity and breed of the female, and the effects of service bull were considered simultaneously. The overall correlation with NRR was low. Motility before or after freezing never accounted for more than $1 \%$ of the variation in any of the adjusted NRR. These results showed that the remaining variation in motility was a poor predictor of NRR, which still showed a substantial variation between bulls. The significant $b-$ values varied between 0.13 and 0.24 . A motility threshold level of $50 \%$, which is often stipulated for approval of the semen after freezing, does not seem to be the optimal choice. In order to avoid unnecessary culling, it is therefore advisable to reduce the level below which ejaculates should be rejected. The examination and selection for fertility should be completed by direct recording and evaluation of NRR. How far the motility level should be lowered to allow bulls to be tested for fertility in the field warrants investigation by utilizing semen with different degrees of reduced motility.
\end{abstract}

\section{Al bull / sperm motility / non-return rate / prediction}

Résumé - Effet de la motilité du sperme de taureau laitier sur le taux de non-retour obtenu avec des taureaux sélectionnés. Cette étude avait pour objet de voir si la variation de la motilité du sperme, après une présélection des taureaux selon ce caractère, a des conséquences sur te taux de non-retour des inséminations artificielles. Les données de motilité avant et après congélation de la semence ainsi que les données de non-retour de 117 jeunes taureaux, chacun avec au moins 100 inséminations, ont été analysées. Deux races de taureaux dans 2 centres d'IA ont servi pour les analyses réalisées séparément pour chaque centre. Les relations entre la motilité et la fertilité ont été étudiées par l'analyse de régressions linéaires entre ces paramètres, en considérant simultanément les effets fixes des troupeaux et année, mois et numéro d'insémination, parité et race des femelles, et les effets des taureaux. La corrélation globale avec les taux de non-retour est faible. La motilité avant ou après congélation n'explique pas plus de $1 \%$ de la variation des taux de nonretour, lesquels présentent encore une variation importante entre taureaux. Les valeurs significatives de b varient entre 0,13 et 0,24 ; plusieurs coefficients présentent même une valeur négative, mais non significative. Le seuil de motilité de $50 \%$, souvent proposé pour accepter la semence après congélation, ne semble pas satisfaisant. Pour éviter l'élimination inutile d'éjaculats, il convient donc de déduire ce seuil. Des recherches complémentaires sont nécessaires pour préciser le niveau à partir duquel la motilié des éjaculats devient discriminante pour la fertilité des taureaux. 


\section{INTRODUCTION}

In Sweden, the culling rate among young bulls according to fertility traits in Al studs is about $30 \%$, which is higher than in most other countries for the corresponding traits (Bernes, 1981; Graffer et al, 1988). About half of such culling is attributable to laboratory examinations of the semen. Semen quality can be related to viability and morphology (Saacke et al, 1980). Visual assessment of the proportion of motile spermatozoa is the most commonly used viability test to predict fertility. In Sweden, sperm motility is currently one of the quality criteria applied to spermatozoa in frozen/thawed semen (Söderqvist, 1991).

The most common measure of fertility under practical farm conditions is the nonreturn rate (NRR). Although NRR is an indirect measure of conception rate, it is considered as a reliable measure of conception rate if only first services are evaluated (Oltenacu and Foote, 1976).

There is little doubt that objective measurements of sperm motility, acrosomal status or other characteristics are significantly correlated with fertility (Amann, 1989). In general, studies have shown a positive correlation between fertility and many semen quality characteristics, although the closeness of the relationship varied widely (Saacke et al, 1980). Such a variation may depend on different numbers as well as proportions of motile sperm in the semen doses.

The number of young bulls culled for semen quality reasons without being tested in the field has been rather high in Sweden. The total discarding rate of semen collections during the studied period was 14.2 and $17.7 \%$ in Nordavel and Falkenberg, respectively. This prompted a discussion about whether motility really is a useful predictor of NRR and which culling practices would also be appropriate to consider other traits.

The aim of this study was to establish whether the remaining variation in sperm motility, after applying preselection to bulls based on this characteristic, had any impact on the achieved fertility as measured by NRR in comprehensive field data on Swedish dairy cattle.

\section{MATERIALS AND METHODS}

The data originated from 2 different $\mathrm{Al}$ studs in Sweden, Låglandsavel Falkenberg $(F)$ and Nordavel $(N)$. The semen data were recorded in the normal semen collection routine between September 1983 and August 1985. The NRR data were based on single inseminations recorded during the period from 1983 to 1985 . The structure of the material is shown in table I.

\section{Recording and evaluation procedures}

The fresh semen was evaluated immediately after each collection. When a service bull ejaculated more than once on the same collection day it was not possible to distinguish between the ejaculates after freezing, as the 2 ejaculates were pooled when frozen and assigned the same collection code. The structure of the data is shown in table I. The semen characteristics were recorded for each ejaculate. This procedure included measuring the volume (mi) and determining motility subjectively under a phasecontrast microscope at $+37^{\circ} \mathrm{C}$ and a magnification of 450 . Motility was evaluated visually as the percentage of forward-motile sperm cells. Spermatozoal concentration was determined spectrophotometrically. The turbidity was compared with a known standard. Total number of sperm cells per ejaculate was calculated by multiplying the concentration (per $\mathrm{ml}$ ) by the total volume. The studs had different set standards for the concentration $88(N)$ and $70(F) \times$ $10^{6}$ motile sperm cells per $\mathrm{ml}$, giving $22(N)$ and 17.5 (F) $\times 10^{6}$ motile sperm cells per semen dose (ministraw, $0.25 \mathrm{ml}$ ). The assessment of motility after freezing and thawing was normally made on 1-2 doses per collection. The exami- 
Table I. Structure of the material.

Alstud/breed Nordavel/SRB a Falkenberg/SLB ${ }^{\text {b }}$

No of service bulls
No of all services
No of $\mathrm{HY}$ c
Mean No of services/bull (range)
No of 1 st services
No of $\mathrm{HY}$ c
Mean No of services/bull (range)

58

53792

11912

$927(160-1694)$

27057

9614

$466(73-977)$
59

33421

10533

$566(308-848)$

16161

7524

a SRB: Swedish Red and White cattle; b SLB: Swedish Friesian; ${ }^{c}$ HY: herd-year combinations.

nation after freezing was a blind-test. The established minimum standards for motility varied slightly between Al studs. Minimum pre-freezing motility was $60-70 \%$ forward-motile sperm cells and for post-freezing motility it was $45-50 \%$. Ejaculates that did not meet the minimum standard set by each Al stud veterinarian for motility before and after freezing were discarded. Motilities before and after freezing were considered as 2 different traits in the analyses (Stälhammar et al, 1989, 1994).

Laboratory evaluations of semen from young Al bulls were correlated with NRR ascribed to these particular bulls when used randomly on a variety of farms and age categories of females. NRR within 28, 56 and $168 \mathrm{~d}$ after senvice were used as measures of fertility.

\section{Methods}

In the analyses based on single inseminations adjustments were made for herd-year effects, the effects of month and order number of insemination, breed and parity of the female as well as for the service bull. A polynomial regression model was applied to investigate the impact of motility on the adjusted NRR. The least-squares method of fitting constants was used, as applied in Harvey's LSMLMW program (Haney, 1985). The 2 sets of data were analysed separately due to poor overlapping, since they covered 2 different breeds and areas.
The model applied was:

$Y_{i j k l m n o}=\mu+H Y_{i}+P_{j}+S_{k}+N_{l}+B_{m}+M_{n}+$ $b_{1}\left(x_{1, j k l m n o}-\bar{x}_{1}\right)+b_{2}^{\prime}\left(x_{1 j k k m n o}^{2}-\bar{x}_{1}^{2}\right)+e_{i j k l m n o}$

where:

$Y_{i j k i m n o}$ is the recorded NRR (value 0 or 1) within 28,56 or $168 \mathrm{~d}$ of service;

$\mu$ is least-squares mean;

$H Y_{i}$ is effect of th herd-year of insemination;

$P_{j}$ is effect of th parity of female $(j=1 \ldots 6)$;

$S_{k}$ is effect of $k$ th service bull;

$N_{\text {i }}$ is effect of th order number of insemination within service period $(I=1 \ldots 5)$;

$B_{m}$ is effect of $m$ th breed of female $(m=1 . . .3)$

$M_{n}$ is effect of $n$th month of insemination $(n=$ 1...12);

$b_{1}, b_{2}$ are the linear and quadratic regressions of NRR on motility before $\left(x_{1}\right)$ and after $\left(x_{2}\right)$ freezing, respectively;

$e_{i j k m n o}$ is the residual effect.

All effects in the model were considered fixed. The effect of herd-year was absorbed into the other fixed effects. Analyses were performed both with all services included and with NRR based on first services only. Parity was assigned to 6 classes: heifers; $1-4$ lactation cows; and cows including 5th and higher parities. Three breed groups of females were present, Swedish Red and White Cattle (SRB) and Swedish Friesian (SLB), and crossbreds be- 
tween SRB and SLB. All service bulls included, except 3 , had records from at least 100 inseminations (table I).

Two reduced models were compared with the full model for the coefficient of determination.

The reason why no technician is taken into the model is that effects of technician are rather confounded with the heard-year effects, and thus they are indirectly accomodated for in the analyses. Furthermore, it can partly be explained by the recording system in Sweden. Studies by Janson (1980) have shown that the effect of technician is of rather low importance. The results for each technician are followed up every month. As a result of this procedure the fertility results of Swedish technicians seem to be fairly uniform.

\section{RESULTS}

The unadjusted bull means $(\bar{x})$ with standard deviations (SD) for NRR and motility together with the range between bulls are shown in table II. Attention is drawn to the low SD of motility, which shows that the whole scale was not used when assessing motility. It is obvious that the non-adjusted NRR varies considerably between bulls even after preselection based on motility.
The full model explained between 25 and $50 \%$ of the variation in NRR, mainly due to the effect of herd-year and almost independent of motility (table III). The same coefficient of determination was obtained for the model whether motility before or after freezing and thawing was included. The effect of service bull explained less than $1 \%$ of the variation in the adjusted NRR when motility was held constant.

All fixed effects, except breed of female, were significant. The regression coefficients were found significant only in $N$. In this case there were also differences in the impact of motility on NRR according to whether it was assessed before or after freezing. Significant regression coefficients $(P<0.01)$ of the NRR were generally obtained for motility before freezing (tables IV and $V$ ) while poorer relationships were found with post-thaw motility. The relationships, if any, seem to be linear but weak in the range of motilities studied. The magnitude of the coefficients of regression indicates that a change in motility of 10 percentage units gives at most a corresponding positive change of $1-2 \%$ units in adjusted NRR (figs 1 and 2). Several of the non-significant coefficients were even neg-

Table II. Unadjusted bull means $(\bar{x})$ with standard deviations (SD) for NRR and motility and the range in NRR and motility before and after freezing.

\begin{tabular}{|c|c|c|c|c|c|}
\hline \multicolumn{3}{|c|}{ Nordavel } & \multicolumn{3}{|c|}{ Falkenberg } \\
\hline $\bar{x}$ & $S D^{a}$ & Range & $\bar{x}$ & SD a & Range \\
\hline 75.8 & 3.5 & $68-83$ & 77.2 & 3.9 & $66-86$ \\
\hline 65.9 & 4.4 & $53-77$ & 68.9 & 4.3 & $54-79$ \\
\hline 57.3 & 5.1 & $33-68$ & 62.3 & 4.6 & $52-74$ \\
\hline 69.6 & 3.3 & $50-80$ & 69.5 & 2.3 & $60-80$ \\
\hline 49.3 & 2.6 & $40-60$ & 54.1 & 3.3 & $40-70$ \\
\hline
\end{tabular}

\footnotetext{
a Means and SD were calculated on individual bull non-return and motility results, respectively, with $n=58$ service bulls in Nordavel and $n=59$ service bulls in Falkenberg. Motility means were based on 2-4 ejaculates per bull.
} 
Table III. Coefficients of determination ( $\left.R^{2} \%\right)$ for full and reduced models in analyses with first services.

\begin{tabular}{|c|c|c|c|c|c|c|}
\hline \multirow[t]{3}{*}{ Model } & \multicolumn{6}{|c|}{ NRR days } \\
\hline & \multicolumn{3}{|c|}{ Nordaval $\mathrm{R}^{2}(\%)$} & \multicolumn{3}{|c|}{ Falkenberg $\mathrm{R}^{2}(\%)$} \\
\hline & 28 & 56 & 168 & 28 & 56 & 168 \\
\hline Full a & 40.3 & 39.5 & 39.7 & 51.7 & 51.8 & 51.4 \\
\hline Reduced b & 40.3 & 39.5 & 39.6 & 51.7 & 51.8 & 51.4 \\
\hline Reduced $\mathrm{C}$ & 1.0 & 1.4 & 1.5 & 1.8 & 1.9 & 1.8 \\
\hline
\end{tabular}

a Full model: herd-year, month of insemination, parity, cow breed, service bull and regression on motility either before or after freezing; ${ }^{b}$ reduced model: as in full model but without the regression; ${ }^{c}$ reduced model: as in full model but without the effect of herd-year.

Table IV. Estimated coefficients of regression of NRR on motility values before and after freezing in analyses using all services.

\begin{tabular}{|c|c|c|c|c|c|c|c|}
\hline \multirow[t]{3}{*}{ Al unit } & \multirow[t]{3}{*}{ NRR } & \multicolumn{3}{|c|}{ Motility before freezing } & \multicolumn{3}{|c|}{ Motility after freezing } \\
\hline & & \multirow{2}{*}{$\begin{array}{c}\text { Linear } \\
b\end{array}$} & \multicolumn{2}{|c|}{ Quadratic } & \multirow{2}{*}{$\underset{b}{L}$} & \multicolumn{2}{|c|}{ Quadratic } \\
\hline & & & $b_{1}$ & $b_{2}$ & & $\mathrm{~b}$, & $b_{2}$ \\
\hline \multirow[t]{3}{*}{$N$} & 28 & $0.15^{\star *}$ & 0.15 & -0.01 & 0.06 & 0.07 & -0.00 \\
\hline & 56 & $0.20^{\star *}$ & 0.20 & -0.01 & 0.13 & 0.16 & -0.01 \\
\hline & 168 & $0.21^{\star \star}$ & 0.22 & $-0.02^{* *}$ & $0.13^{*}$ & 0.15 & -0.01 \\
\hline \multirow[t]{3}{*}{$F$} & 28 & -0.13 & -0.11 & 0.03 & -0.01 & 0.01 & -0.01 \\
\hline & 56 & -0.10 & -0.10 & -0.00 & 0.05 & 0.06 & -0.01 \\
\hline & 168 & -0.03 & 0.04 & -0.01 & 0.11 & 0.11 & 0.00 \\
\hline
\end{tabular}

${ }^{*} P<0.05 ;{ }^{* *} P<0.01$.

ative. Only for 168-d NRR with all services included was there a significant quadratic regression coefficient obtained.

\section{DISCUSSION}

In order to study the true relation between semen characteristics and the paternal contribution to a successful conception of farm management, season and technician should be taken into account. NRR of bulls can be corrected for these influences (den Daas, 1992). Although this was done in this study through the herd-year effects, other possible reasons for not finding a close correlation between motility and NRR must be looked for. One cause might 
Table V. Estimated coefficients of regression of NRR on motility values before and after freezing in analyses using first services.

\begin{tabular}{|c|c|c|c|c|c|c|c|}
\hline \multirow[t]{3}{*}{ Al unit } & \multirow[t]{3}{*}{$N R R$} & \multicolumn{3}{|c|}{ Motility before freezing } & \multicolumn{3}{|c|}{ Motility after freezing } \\
\hline & & \multirow{2}{*}{$\underset{b}{\text { Linear }}$} & \multicolumn{2}{|c|}{ Quadratic } & \multirow{2}{*}{$\underset{b}{\operatorname{Linear}}$} & \multicolumn{2}{|c|}{ Quadratic } \\
\hline & & & $b_{1}$ & $\mathrm{~b}_{2}$ & & $b_{1}$ & $b_{2}$ \\
\hline \multirow[t]{3}{*}{$N$} & 28 & 0.15 & 0.15 & -0.01 & -0.01 & -0.00 & -0.00 \\
\hline & 56 & $0.19^{\star}$ & 0.19 & -0.02 & 0.15 & 0.14 & 0.00 \\
\hline & 168 & $0.24^{*}$ & 0.24 & -0.03 & 0.14 & 0.14 & 0.00 \\
\hline \multirow[t]{3}{*}{$F$} & 28 & 0.08 & 0.09 & 0.02 & -0.23 & -0.21 & -0.01 \\
\hline & 56 & 0.11 & 0.09 & -0.05 & -0.02 & -0.03 & 0.00 \\
\hline & 168 & 0.16 & 0.14 & -0.03 & 0.03 & -0.01 & 0.02 \\
\hline
\end{tabular}

$* P<0.05$

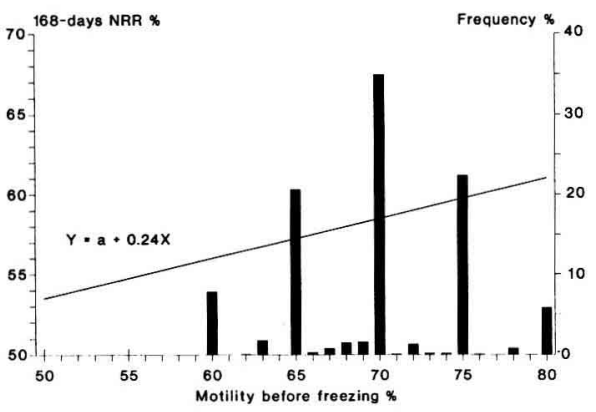

Fig 1. 1st service data from Nordavel. The linear regression fitted for the equation showing the impact of motility pre-freezing on 168-d adjusted NRR based on single services. The frequencies of assessed motility values in percentage units are depicted as bars.

be the reduced variation due to the culling of bulls by discarding ejaculates both before and after freezing/thawing. Reductions in the viability of individual spermatozoa would then be masked by the remaining competent cells (Salisbury et al, 1978). It can also be discussed whether it

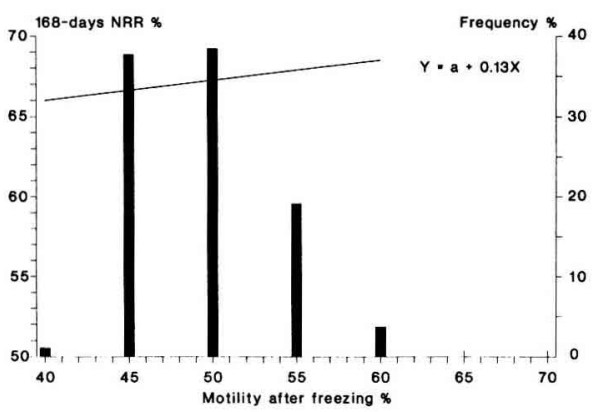

Fig 2. All service data from Nordavel. The linear regression fitted for the equation showing the impact of motility post-freezing on 168-d adjusted NRR based on single services. The frequencies of assessed motility values in percentage units are depicted as bars.

is the actual number of motile sperms inseminated, rather than the percentage of motile sperms, that is related to fertility (Saacke et al, 1991). This is also maintained by Pace et al (1981), who showed that the number of spermatozoa inseminated was positively correlated $(P<0.05)$ to 
90-d NRR. Den Daas (1992) concluded that a successful penetration of the oocyte depends on the quality of the inseminated spermatozoa extrinsic sperm quality.

Budworth et al (1988), however, did not find any significant correlations between 75-d NRR and parameters of sperm movement, though for a 'competitive fertility index' the correlation with percent motile spermatozoa was significant $(r=0.80)$. This index is a measure of relative fertility, where equal numbers of spermatozoa from 2 bulls are inseminated and the sire of each calf is established by blood-typing.

A field experiment with semen not selected for motility or other semen quality traits would better clarify the real biological relationship between motility and NRR. An entirely objective method for motility assessment would also be necessary. Although there is evidence that evaluations of track motility, an objective approach for evaluating sperm motility, are only slightly more reliable in predicting fertility than the method of replicated visual estimates of sperm motility (Saacke et al, 1980).

In a Swedish study, Håård (1989) showed that semen with less than $50 \%$ motility after freezing seemed to have lower 56-d NRR than semen with higher than $50 \%$ post-freezing motility. There was no difference in NRR between ejaculates when the motility after freezing was at least $50 \%$, possibly due to the large number of sperm cells per dose used at that time.

For the Al stud, the discarding of ejaculates and culling of bulls has the objective of eliminating poor semen, which seems to have been achieved. However, it is also important not to discard semen and to cull bulls that would allow a good fertilizing ability despite questionable motility results. From both scientific and practical points of view it is therefore of the utmost importance to assess the real relationship between motility and NRR, even when ejacu- lates with a post-thaw motility below $50 \%$ are used, and maybe with a different total number of spermatozoa in the dose.

Elliot (1978) stated: "Obviously if all semen selected for use in $\mathrm{Al}$ is at or above the optimum level for number of motile sperm no measurable relationship between the number of motile sperm and fertility wouid result". This is probably the case with semen routinely used in Sweden. Thus; the question remains as to how much above the optimum the present semen selection practice is.

Both a low overall correlation with NRR and the fact that motility before or after freezing do not account for more than $1 \%$ of the variation in any of the adjusted NRR, showed that motility in the present range had hardly any impact on NRR. When interpreting the regression lines, one must bear in mind the frequency distribution of motility, which showed that the estimated regression coefficients were valid only in the interval $40-80 \%$ motility (figs 1 and 2).

\section{CONCLUSIONS}

It has been shown that the adjusted NRR still varies significantly between bulls, even at motility levels above the normally applied minimum threshold for semen approval. Neither of the motility traits was a good predictor of NRR, once semen had already been preselected according to these criteria.

Since the relationship between motility and adjusted NRR, indicated by the regression coefficients, was linear though very weak or non-significant for post-thaw motilities around $50 \%$, this threshold level does not seem to be the optimal choice. This was further emphasized by the fact that motility accounted for less than $1 \%$ of the variation in the adjusted NRR. 
It is suggested that motility levels be reduced for approval and that bulls be selected more directly on NRR, since NRR still showed a considerable variation between bulls. The size of the proposed reduction warrants further investigation in order to establish an optimum motility level for semen approval before being tested in the field for fertility.

The present study has clearly demonstrated the limitations of motility evaluations as presently being practiced as a single criterion for selection of young bulls to enter Al. Certainly, additional methods for assessing semen quality, such as the functionality of sperm and computerassisted motility assessments, need to be developed and analysed as fertility predictors.

\section{ACKNOWLEDGMENTS}

Thanks are expressed to the Swedish Association for Livestock Breeding and Production (SHS) and the bull studs at Falkenberg and $\mathrm{Ny}$ land for supplying data. The study was supported financially by the Farmers Research Council for Information and Development, which is gratefully acknowledged.

\section{REFERENCES}

Amann RP (1989) Can the fertility potential of a seminal sample be predicted accurately? $J$ Androl 2, 89-98

Bernes $G$ (1981) Culling reasons and fertility in young Al bulls (in Swedish). Technical Report 95. Swedish University of Agricultural Sciences, Dept of Animal Breeding and Genetics, Box 7023, S-750 07 Uppsala

Budworth PR, Amann RP, Chapman PL (1988) Relationships between computerized measurements of motion of frozen-thawed bull spermatozoa and fertility. J Androl 9, 4154
Den Daas N (1992) Laboratory assessment of semen characteristics. Anim Reprod Sci 28, 87-94

Elliot FI (1978) Significance of semen quality. In: Physiology of Reproduction and Artificial Insemination of Cattle (GW Salisbury, NL VanDemark, JR Lodge, eds) WH Freeman and Co, San Francisco, 428-441

Graffer T, Solbu H, Filseth O (1988) Semen production in artificial insemination bulls in Norway. Theriogenology 30, 1011-1021

Hanwey WR (1985) User's Guide for LSMLMW. Ohio State University

Håård M (1989) Old and new problems from the practical routines at the Al studs, which can have an impact on semen quality and the fertility of bulls (in Swedish). Allmänt veterinärmöte, Sveriges Lantbruksuniversitet, Uppsala, Kompendium, 66-71

Janson L (1980) Studies on fertility traits in dairy cattle. Department of Animal Breeding and Genetics, Swedish University of Agricultural Sciences, Uppsala. Thesis Report 45

Oltenacu EAB, Foote RH (1976) Monitoring fertility of Al programs: Can Non-return Rate do the job? Proceedings, 4th Technical Conference on Al and Reproduction. NAAB, 6168

Pace MM, Sullivan JJ, Elliott FI, Graham EF, Coulter GH (1981) Effects of thawing temperature, number of spermatozoa and spermatozoal quality on fertility of bovine spermatozoa packaged in 0.5-ml French straws. J Anim Sci 53 (3), 693-701

Saacke RG, Vinson WE, O'Connor ML et al (1980) The relationship of semen quality and fertility: a heterospermic study. Proceedings, 8th Technical Conference on Al and Reproduction, NAAB, 71-78

Saacke RG, DeJarnette JM, Nebel RL, Nadir S (1991) Assessing bull fertility. Proceedings, Annual Meeting of Society for Theriogenology, August 16-17, San Diego, California. 5669

Salisbury GW, VanDemark NL, Lodge JR (1978) Physiology of Reproduction and Artificial Insemination of Cattle. WH Freeman and Co, San Francisco

Stålhammar EM, Janson L, Philipsson J (1989) Genetic studies on fertility in Al bulls. I Age, season and genetic effects on semen charac- 
teristics in young bulls. Anim Reprod Sci 19, 1-17

Stålhammar EM, Janson L, Philipsson J (1993) Genetic studies on fertility in Al bulls. II. Environmental and genetic effects on non-return rates of young bulls. Anim Reprod Sci (in press)
Söderqvist L (1991) Semen characteristics and fertility in AI bulls. With special reference to sperm motility, ATP content, sperm morphology, and spermatogenesis. Department of Obstetrics and Gynaecology, Faculty of Veterinary Medicine, Swedish University of Agricultural Sciences, Uppsala. Thesis 